\title{
Cystatin C predicts renal function impairment after partial or radical tumor nephrectomy
}

\author{
Mike Wenzel $\mathrm{I}^{1,2}$ ( $\cdot$ Hang $\mathrm{Yu}^{3} \cdot$ Annemarie Uhlig ${ }^{4} \cdot$ Christoph Würnschimmel ${ }^{2,5} \cdot$ Manuel Wallbach $^{6} \cdot$ Andreas Becker $^{1}$. \\ Margit Fisch $^{3} \cdot$ Felix K. H. Chun ${ }^{1}$. Christian P. Meyer ${ }^{3} \cdot$ Marianne Leitsmann $^{4}$
}

Received: 3 June 2021 / Accepted: 9 July 2021 / Published online: 16 July 2021

(c) The Author(s) 2021

\begin{abstract}
Purpose To test the value of preoperative and postoperative cystatin $\mathrm{C}(\mathrm{Cys} \mathrm{C})$ as a predictor on kidney function after partial $(\mathrm{PN})$ or radical nephrectomy $(\mathrm{RN})$ in renal cell carcinoma $(\mathrm{RCC})$ patients with normal preoperative renal function.

Methods From 01/2011 to 12/2014, 195 consecutive RCC patients with a preoperative estimated glomerular filtration rate $($ GFR $)>60 \mathrm{ml} / \mathrm{min} / 1.73 \mathrm{~m}^{2}$ underwent surgical RCC treatment with either PN or RN. Logistic and linear regression models tested for the effect of CysC as a predictor of new-onset chronic kidney disease in follow-up (eGFR $\left.<60 \mathrm{ml} / \mathrm{min} / 1.73 \mathrm{~m}^{2}\right)$. Moreover, postoperative $\mathrm{CysC}$ and creatinine values were compared for kidney function estimation.

Results Of 195 patients, 129 (66.2\%) underwent PN. In postoperative and in follow-up setting (median 14 months, IQR $10-20$ ), rates of eGFR $<60 \mathrm{ml} / \mathrm{min} / 1.73 \mathrm{~m}^{2}$ were 55.9 and $30.2 \%$. In multivariable logistic regression models, preoperative CysC [odds ratio (OR): 18.3] and RN (OR: 13.5) were independent predictors for a reduced eGFR $<60 \mathrm{ml} / \mathrm{min} / 1.73 \mathrm{~m}^{2}$ in follow-up (both $p<0.01$ ), while creatinine was not. In multivariable linear regression models, a difference of the preoperative CysC level of $0.1 \mathrm{mg} / \mathrm{dl}$ estimated an eGFR decline in follow-up of about $5.8 \mathrm{ml} / \mathrm{min} / 1.73 \mathrm{~m}^{2}$. Finally, we observed a plateau of postoperative creatinine values in the range of $1.2-1.3 \mathrm{mg} / \mathrm{dl}$, when graphically depicted vs. postoperative CysC values ('creatinine blind area').

Conclusion Preoperative CysC predicts renal function impairment following RCC surgery. Furthermore, CysC might be superior to creatinine for renal function monitoring in the early postoperative setting.
\end{abstract}

Keywords Cystatin C $\cdot$ Nephrectomy $\cdot$ Renal cell carcinoma $\cdot$ GFR $\cdot$ Acute kidney injury

Mike Wenzel

Mike.Wenzel@kgu.de

1 Department of Urology, University Hospital Frankfurt, Goethe University Frankfurt, Frankfurt, Germany

2 Cancer Prognostics and Health Outcomes Unit, Division of Urology, University of Montreal Health Center, Montreal, QC, Canada

3 Department of Urology, University Medical Center Hamburg-Eppendorf, Hamburg, Germany

4 Department of Urology, University Medical Center Göttingen, Göttingen, Germany

5 Martini-Klinik Prostate Cancer Center, University Hospital Hamburg-Eppendorf, Hamburg, Germany

6 Department of Nephrology, University Medical Center Göttingen, Göttingen, Germany

\section{Introduction}

In localized renal cell carcinoma (RCC), surgical treatment with either nephron-sparing partial nephrectomy (PN) or radial nephrectomy $(\mathrm{RN})$ is associated with excellent oncological outcomes [1-3]. However, all nephrectomy patients are at increased risk for renal function decline occurring as short-term acute kidney injury (AKI) or subsequent chronic kidney disease (CKD) [4, 5]. Within this context, RCC patients are at higher risk for postoperative new-onset cardiovascular morbidity and in the further mortality $[6,7]$. In consequence, it is suggested to perform nephron-sparing surgery, whenever possible, as recommended in EAU guidelines [8]. In several studies, the estimated glomerular filtration rate (eGFR) or patients' comorbidity profile was associated with postoperative AKI or long-term CKD after PN or RN [4-6, 9-12]. 
Moreover, multiple studies showed a better accuracy of cystatin $\mathrm{C}$ (CysC), relative to serum creatinine, to estimate kidney function through eGFR in surgically and non-surgically treated patients [13-15]. Several studies showed that CysC predicts short-term postoperative AKI and long-term kidney impairment [15-18]. Additionally, it was also found that creatinine, which is used in hospital standard routine, may over- and underestimate kidney function regarding patients' age category [19]. In consequence, creatinine may not be the best parameter for kidney function monitoring after RN or PN and few if any is known about the role of CysC in surgically treated RCC patients regarding long-term kidney function. These observations make it necessary to investigate if CysC is potentially a better marker for risk stratification, especially in patients with mildly to moderately impaired kidney function and within the "creatinine blind area', to counsel and classify patients even more accurate according to risk profiles and possibly postoperative monitoring [20].

We addressed this knowledge gap and hypothesized that CysC may play a crucial role in outcome measurements of kidney function after surgical treatment with $\mathrm{RN}$ or PN for $\mathrm{RCC}$ patients. Moreover, we postulated that $\mathrm{CysC}$ may be less influenced by patient's age than creatinine.

\section{Methods}

\section{Study population}

The current study was performed in accordance with the Declaration of Helsinki and approved by the local ethic committee of the University Hamburg-Eppendorf (number PV4219). All consecutive patients who underwent surgical treatment with either PN or PN for RCC between 01/2011 and 12/2014 at the Department of Urology, University Medical Center Hamburg-Eppendorf, Germany, were retrospectively identified. Exclusion criteria consisted of patients with preoperative impairment of kidney function, defined as eGFR $<60 \mathrm{ml} / \mathrm{min} / 1.73^{2}(n=54)$, non-RCC postoperative histology $(n=17)$, surgical treatment for kidney trauma $(n=1)$ and death during follow-up $(n=9)$. These selection criteria resulted in 195 eligible surgically treated patients.

\section{Patient characteristics, renal function and AKI evaluation}

From patient's data files patient's baseline characteristics according to blood, urine and tumor values/characteristics were collected. All RCC patients were surgically treated with either open, laparoscopic or robotic RN or PN. Preoperative and postoperative unsuspicious $\mathrm{Cys} C$ values were defined as $\leq 0.96 \mathrm{mg} / 1$, as previously described [21].
Provided data regarding eGFR, were calculated in accordance with the four variable MDRD Study Equation: GFR in $\mathrm{ml} / \mathrm{min} / 1.73^{2}=186 \times($ S-Creatinine -1.154$) \times$ (age -0.203 ) $\times 1.212$ (if African American race/ethnicity) $\times 0.742$ (if female sex) [22, 23]. Provided data regarding AKI were defined as either an $\geq 50 \%$ increase of the postoperative blood serum creatinine relative to preoperative blood serum creatinine. Alternatively, it was defined as an absolute increase of the postoperative blood serum creatinine of $\geq 0.3 \mathrm{mg} / \mathrm{dl}$ on first postoperative day after $\mathrm{RN}$ or PN in accordance with the current AKI criteria by KDIGO [24].

\section{Endpoints and follow-up}

Primary endpoint of the study was the assessment of postoperative (day 1) and follow-up kidney function with regard to preoperative and postoperative $\mathrm{CysC}$ blood levels. Kidney function impairment in follow-up was defined as an eGFR $<60 \mathrm{ml} / \mathrm{min} / 1.73^{2}$, in accordance with current definitions [25]. Patients underwent a systematic follow-up through a standardized survey supported by the treating urologist or family doctor. The survey consisted of questions addressing baseline characteristics [e.g., weight, body mass index (BMI) or blood pressure values], new-onset diseases and blood and urine values, if available. Secondary endpoints of the current study consisted of the relationship between first-day postoperative creatinine and $\mathrm{CysC}$ blood values in patients with non-elevated preoperative CysC.

\section{Statistical analyses}

Descriptive statistics included frequencies and proportions for categorical and medians and interquartile ranges (IQR) for continuous variables. The Chi-square, the $t$ test and Kruskal-Wallis tests assessed differences among groups as appropriate.

Uni- and multivariable logistic, as well as linear regression models were fitted to assess the value of CysC as a predictor of kidney function in follow-up after PN or RN. Significant variables in univariable logistic regression models, were included in multivariable models. Moreover, loessplots were used to depict the correlation between first-day postoperative creatinine and postoperative $\mathrm{Cys} C$ in surgically treated RCC patients. Subsequently, same tabulations were made for different age cut-offs and in postoperative AKI patients.

All statistical analyses were performed using the R statistical package system 3.4.3 (R Foundation for Statistical Computing, Vienna, Austria), with a two-sided significance level set at $p<0.05$ [26]. 


\section{Results}

\section{Descriptive baseline characteristics}

Of all eligible 195 patients (Table 1), median age was 60 years and 134 were males (68.7\%). Overall, 129 (66.2\%) underwent PN vs. 66 (33.8\%) RN. Open surgery was performed predominately (77.4\%), followed by laparoscopic (15.9\%) and robotic $(6.7 \%)$ approaches. Preoperative creatinine, eGFR and CysC were respectively $0.9 \mathrm{mg} / \mathrm{dl}$ (IQR $0.8-1.0$ ), $88 \mathrm{ml} / \mathrm{min} / 1.73 \mathrm{~m}^{2}$ (IQR $76-103$ ) and $0.8 \mathrm{mg} / \mathrm{l}$ (IQR 0.7-0.9). In the entire cohort, rates of postoperative and follow-up eGFR $<60 \mathrm{ml} / \mathrm{min} / 1.73 \mathrm{~m}^{2}$ were respectively 55.9 and $30.2 \%$. In particular, at follow-up, $75.9 \%$ of patients had CKD G3a (eGFR $45-59 \mathrm{ml} / \mathrm{min} / 1.73 \mathrm{~m}^{2} /$ and $24.1 \%$ of had CKD G3b (eGFR 30-44 ml/min/1.73 $\mathrm{m}^{2}$ ).

Further stratification according to postoperative elevated or normal CysC level was made (Table 1). Here, 105 (53.8\%) of all 195 patients had elevated CysC levels postoperatively. Of these, $74(70.5 \%)$ and $72(68.6 \%)$ exhibited postoperative AKI and eGFR $<60 \mathrm{ml} / \mathrm{min} / 1.73 \mathrm{~m}^{2}$. Moreover, patients with elevated postoperative $\mathrm{CysC}$ were older (61 vs. 59), exhibited higher rates of preoperative diabetes $(20.0$ vs. $5.6 \%$, all $p<0.05)$ than patients with normal postoperative CysC. Additionally, patients with postoperative elevated $\mathrm{Cys} C$ more frequently underwent RN (48.6 vs. 16.7\%) and exhibited larger tumor sizes (4.6 vs. $3.4 \mathrm{~cm})$.

\section{Cystatin $\mathrm{C}$ as a predictor for kidney function impairment at follow-up}

Median follow-up duration was 14 months (IQR 10-20) and of all patients, $46.2 \%(n=95)$ participated in the follow-up. At baseline, median eGFR was 88 vs. $67 \mathrm{ml} /$ $\mathrm{min} / 1.73 \mathrm{~m}^{2}$ at follow-up $(p=0.2)$. In univariable logistic regression models (Table 2), preoperative CysC [odds ratio (OR): 9.9, confidence interval (CI): 3.2-24.9] and postoperative CysC (OR: 6.5, CI: 2.4-21.3, both $p<0.001$ ) were associated with an eGFR $<60 \mathrm{ml} / \mathrm{min} / 1.73 \mathrm{~m}^{2}$. Moreover, tumor size (OR: 1.41, CI: 1.2-1.8), postoperative AKI (OR: 4.3, CI: 1.5-13.8) and RN (OR: 16.6, CI: 5.9-51.9) were associated with an eGFR $<60 \mathrm{ml} / \mathrm{min} / 1.73 \mathrm{~m}^{2}$ at follow-up (all $p<0.01$ ).

In multivariable logistic regression models, preoperative CysC (OR: 9.3, CI: 1.8-67.8) and RN (OR: 8.3, CI: 2.1-38.7) were independent predictors for a reduced eGFR $<60 \mathrm{ml} / \mathrm{min} / 1.73 \mathrm{~m}^{2}$ at follow-up (both $p \leq 0.01$ ). Conversely, postoperative CysC was not associated with an eGFR $<60 \mathrm{ml} / \mathrm{min} / 1.73 \mathrm{~m}^{2}$ at follow-up $(p=0.3)$. Additionally, when preoperative creatinine was used and adjusted for the same covariates, creatinine did not achieve independent predictor status for an eGFR $<60 \mathrm{ml} /$ $\mathrm{min} / 1.73 \mathrm{~m}^{2}$ at follow-up $(p=0.2)$.

We further validated these observations in multivariable linear regression models (Table 3). Here, preoperative CysC (OR: -5.8 , CI: $-9.7-(-2.03), p<0.01$ ) was also independently influencing the patients' eGFR at follow-up. This means that a preoperative increase of the CysC level of $0.1 \mathrm{mg} / \mathrm{dl}$ was associated with an eGFR decline of $5.8 \mathrm{ml} /$ $\min / 1.73 \mathrm{~m}^{2}$ at follow-up.

\section{Comparison between postoperative cystatin C vs. creatinine}

To further investigate the performance of postoperative CysC in surgically treated patients, we plotted postoperative $\mathrm{Cys} C$ values vs. creatinine values in all examined patients (Fig. 1A). Here, we observed a linear relationship between postoperative cystatin $\mathrm{C}$ and postoperative creatinine. The exception consisted of the range of postoperative CysC values between $0.9-1.0 \mathrm{mg} / \mathrm{l}$. Here, a plateau at a postoperative creatinine range of approximately $1.2-1.3 \mathrm{mg} / \mathrm{dl}$ was observed. We further validated this observation in postoperative AKI patients (Fig. 1B). Moreover, we validated this observation in different age subgroups ( $\geq 50, \geq 60, \geq 70,<50$ years, Fig. 2). All stratification yielded virtually same observations.

\section{Discussion}

Several studies suggested CysC as a better marker for kidney function estimations than creatinine, based on CysC's molecular structure and its physiology regarding filtration and reabsorption [14, 27]. However, these assumptions have not been sufficiently validated in contemporary surgically treated RCC cohorts. We hypothesized that CysC may play a crucial role in outcome measurements of kidney function after surgical treatment with either PN or RN for RCC patients. Against this backdrop, our study holds several noteworthy findings.

First, we found that patients with postoperative elevated CysC after RCC surgery were older (61 vs. 59 years), underwent more frequently RN (48.6 vs. $16.7 \%)$ and presented larger tumor sizes ( $4.6 \mathrm{vs} 3.4 \mathrm{~cm}$ ), than patients with normal postoperative CysC level. Moreover, expectedly, patients with elevated postoperative $\mathrm{CysC}$ had a lower preoperative eGFR, and higher creatinine and $\mathrm{CysC}$ values, than patients with normal postoperative CysC. Additionally, patients with postoperative elevated CysC level more frequently exhibited diabetes ( 20 vs. $6 \%$ ). These observations are not surprising, since they validate preoperative selection criteria for patients who are candidates for either PN or RN, as already observed 
Table 1 Descriptive characteristics of 195 patients who underwent either partial (PN) or radical nephrectomy (RN) at the University Hospital Hamburg-Eppendorf, stratified according to postoperative elevated $(\geq 0.96 \mathrm{mg} / \mathrm{dl})$ vs. normal $(<0.96 \mathrm{mg} / \mathrm{dl})$ cystatin c level

\begin{tabular}{|c|c|c|c|c|}
\hline Variable & Overall $n=195$ & $\begin{array}{l}\text { Postoperative normal cystatin } \\
\text { c } n=90(46.2 \%)\end{array}$ & $\begin{array}{l}\text { Postoperative elevated cystatin } \\
\text { c } n=105(53.8 \%)\end{array}$ & $p$ value \\
\hline \multicolumn{5}{|l|}{ Age, years } \\
\hline Median (IQR) & $60(50-70)$ & $59(49-68)$ & $61(53-72)$ & 0.042 \\
\hline \multicolumn{5}{|c|}{ Preoperative creatinine, $\mathrm{mg} / \mathrm{dl}$} \\
\hline Median (IQR) & $0.9(0.8-1.0)$ & $0.8(0.7-0.9)$ & $0.9(0.8-1.1)$ & $<0.001$ \\
\hline \multicolumn{5}{|c|}{ Preoperative eGFR, in $\mathrm{ml} / \mathrm{min} / 1.73 \mathrm{~m}^{2}$} \\
\hline Median (IQR) & $88(76-103)$ & $95(78-106)$ & $83(71-94)$ & $<0.001$ \\
\hline \multicolumn{5}{|c|}{ Preoperative cystatin c, mg/dl } \\
\hline Median (IQR) & $0.8(0.7-0.9)$ & $0.7(0.7-0.8)$ & $0.8(0.7-1.0)$ & $<0.001$ \\
\hline \multicolumn{5}{|l|}{ Tumorsize, $\mathrm{cm}$} \\
\hline Median (IQR) & $4.2(2.4-5.8)$ & $3.4(2.1-4.7)$ & $4.6(3.0-6.5)$ & $<0.01$ \\
\hline \multicolumn{5}{|c|}{ Postoperative creatinine, $\mathrm{mg} / \mathrm{dl}$} \\
\hline Median (IQR) & $1.2(1.0-1.4)$ & $1.1(1.0-1.3)$ & $1.3(1.1-1.6)$ & $<0.001$ \\
\hline \multicolumn{5}{|c|}{ Postoperative eGFR, in $\mathrm{ml} / \mathrm{min} / 1.73 \mathrm{~m}^{2}$} \\
\hline Median (IQR) & $58(48-71)$ & $63(54-78)$ & $52(42-63)$ & $<0.001$ \\
\hline \multicolumn{5}{|c|}{ Postoperative cystatin $\mathrm{c}, \mathrm{mg} / \mathrm{dl}$} \\
\hline Median (IQR) & $1.2(1.0-1.5)$ & $1.1(1.0-1.3)$ & $1.4(1.1-1.7)$ & $<0.001$ \\
\hline \multicolumn{5}{|c|}{ Follow-up eGFR, in $\mathrm{ml} / \mathrm{min} / 1.73 \mathrm{~m}^{2}$} \\
\hline Median (IQR) & $67(53-84)$ & $69(62-89)$ & $63(52-83)$ & 0.3 \\
\hline \multicolumn{5}{|l|}{ Sex } \\
\hline Female & $61(31.3)$ & $33(36.7)$ & $28(26.7)$ & 0.2 \\
\hline Male & $134(68.7)$ & $57(63.3)$ & $77(73.3)$ & \\
\hline \multicolumn{5}{|l|}{ BMI } \\
\hline$\geq 30$ & $46(23.6)$ & $17(18.9)$ & $29(27.6)$ & 0.2 \\
\hline \multicolumn{5}{|l|}{ Type of surgery } \\
\hline PN & $129(66.2)$ & $75(83.3)$ & $54(51.4)$ & 0.001 \\
\hline $\mathrm{RN}$ & $66(33.8)$ & $15(16.7)$ & $51(48.6)$ & \\
\hline \multicolumn{5}{|c|}{ Surgical approach } \\
\hline Robotic & $13(6.7)$ & $8(8.9)$ & $5(4.8)$ & 0.4 \\
\hline Laparoscopic & $31(15.9)$ & $12(13.3)$ & $19(18.1)$ & \\
\hline Open & $151(77.4)$ & $70(77.8)$ & $81(77.1)$ & \\
\hline \multicolumn{5}{|l|}{ Ischemia } \\
\hline Yes & $50(25.6)$ & $30(33.3)$ & $20(19.0)$ & 0.01 \\
\hline \multicolumn{5}{|c|}{ Preoperative hypertension } \\
\hline Yes & $75(38.5)$ & $35(38.9)$ & $40(38.1)$ & 0.7 \\
\hline \multicolumn{5}{|c|}{ Preoperative diabetes } \\
\hline Yes & $26(13.3)$ & $5(5.6)$ & $21(20.0)$ & $<0.01$ \\
\hline \multicolumn{5}{|c|}{ Preoperative proteinuria } \\
\hline Yes & $39(20)$ & $14(15.6)$ & $25(23.8)$ & 0.2 \\
\hline \multicolumn{5}{|l|}{ pT-stage } \\
\hline $\mathrm{T} 1$ & $121(62.0)$ & $56(62.2)$ & $64(61)$ & 0.5 \\
\hline $\mathrm{T} 2$ & $17(8.7)$ & $5(5.6)$ & $13(12.4)$ & \\
\hline $\mathrm{T} 3$ & $11(5.6)$ & $4(4.4)$ & $7(6.7)$ & \\
\hline $\mathrm{T} 4$ & $1(0.5)$ & $0(0)$ & $1(1)$ & \\
\hline \multicolumn{5}{|c|}{ Postoperative proteinuria } \\
\hline Yes & $90(46.2)$ & $58(64.4)$ & $32(30.5)$ & 0.1 \\
\hline \multicolumn{5}{|c|}{ Postoperative acute kidney injury } \\
\hline Yes & $127(65.1)$ & $53(58.9)$ & $74(70.5)$ & 0.1 \\
\hline
\end{tabular}

$I Q R$ interquartile range, $B M I$ body mass index 
Table 2 Univariable and multivariable logistic regression models predicting estimated glomerular filtration rate (eGFR) $<60 \mathrm{ml} / \mathrm{min} / 1.73 \mathrm{~m}^{2}$ in follow-up, after either partial (PN) or radical nephrectomy (RN) for renal cell carcinoma
Table 3 Linear regression models predicting estimated glomerular filtration rate (eGFR) $\mathrm{ml} / \mathrm{min} / 1.73 \mathrm{~m}^{2}$ in follow-up, after either partial (PN) or radical nephrectomy (RN) for renal cell carcinoma

\begin{tabular}{|c|c|c|c|c|c|c|}
\hline & \multicolumn{3}{|c|}{ Univariable } & \multicolumn{3}{|c|}{ Multivariable } \\
\hline & OR & $95 \% \mathrm{CI}$ & $p$ value & OR & $95 \% \mathrm{CI}$ & $p$ value \\
\hline Preoperative cystatin $\mathrm{C}$ & 9.91 & $3.24-24.86$ & $<0.001$ & 18.33 & $2.69-214.88$ & $<0.01$ \\
\hline Postoperative cystatin C & 6.51 & $2.36-21.27$ & $<0.001$ & 1.32 & $0.23-7.77$ & 0.7 \\
\hline Age at diagnosis & 1.04 & $0.99-1.09$ & 0.1 & 1.04 & $0.97-1.13$ & 0.3 \\
\hline Tumor size & 1.41 & $1.15-1.80$ & $<0.01$ & 1.15 & $0.97-1.13$ & 0.3 \\
\hline No postoperative AKI & 1 (Ref.) & - & - & 1 & - & - \\
\hline Postoperative AKI & 4.25 & $1.54-13.84$ & $<0.01$ & 3.35 & $0.57-26.85$ & 0.2 \\
\hline PN & 1 (Ref.) & - & - & 1 & - & - \\
\hline $\mathrm{RN}$ & 16.63 & $5.94-51.87$ & $<0.001$ & 13.52 & $2.85-89.6$ & $<0.01$ \\
\hline BMI & 1.06 & $0.98-1.16$ & 0.2 & 1.12 & $0.98-1.29$ & 0.08 \\
\hline No diabetes & 1 (Ref.) & - & - & 1 & - & - \\
\hline Diabetes & 2.59 & $9.80-8.42)$ & 0.1 & 2.79 & $0.35-25.98$ & 0.3 \\
\hline
\end{tabular}

$O R$ odds ratio, $C I$ confidence interval, $A K I$ acute kidney injury, $B M I$ body mass index

\begin{tabular}{|c|c|c|c|c|c|c|}
\hline & \multicolumn{3}{|l|}{ Univariable } & \multicolumn{3}{|c|}{ Multivariable } \\
\hline & Coefficient & $95 \%$ CI & $p$ value & Coefficient & $95 \% \mathrm{CI}$ & $p$ value \\
\hline Preoperative cystatin c & -7.60 & $-9.79-(-5.40)$ & $<0.001$ & -5.84 & $-9.65-(-2.03)$ & $<0.01$ \\
\hline Postoperative cystatin c & -3.69 & $-4.79-(-2.60)$ & $<0.001$ & -0.02 & $-2.13-2.08$ & 1 \\
\hline Age at diagnosis & -0.51 & $-0.90-(-0.13)$ & $<0.01$ & -0.36 & $-0.74-0.03$ & 0.07 \\
\hline Tumor size & -3.36 & $-4.93-(-1.80)$ & $<0.001$ & -0.33 & $-2.26-1.61$ & 0.7 \\
\hline No postoperative AKI & 1 (Ref) & - & - & 1 & - & - \\
\hline Postoperative AKI & -17.09 & $-25.27-(-8.91)$ & $<0.001$ & -10.62 & $-21.56-0.31$ & 0.056 \\
\hline PN & 1 (Ref) & - & - & 1 & - & - \\
\hline $\mathrm{RN}$ & -25.78 & $-33.41-(-18.15)$ & $<0.001$ & -12.99 & $-24.49-1.49$ & 0.03 \\
\hline BMI & -0.84 & $-1.67-(-0.01)$ & 0.048 & -0.17 & $-1.24-0.91$ & 0.8 \\
\hline Preoperative diabetes & -6.92 & $-19.10-5.25$ & 0.3 & 3.21 & $-10.90-17.31$ & 0.6 \\
\hline Preoperative hypertonia & -5.55 & $-14.92-3.83$ & 0.2 & -1.48 & $-10.60-7.64$ & 0.7 \\
\hline
\end{tabular}

$O R$ odds ratio, $C I$ confidence interval, $A K I$ acute kidney injury, $B M I$ body mass index
A

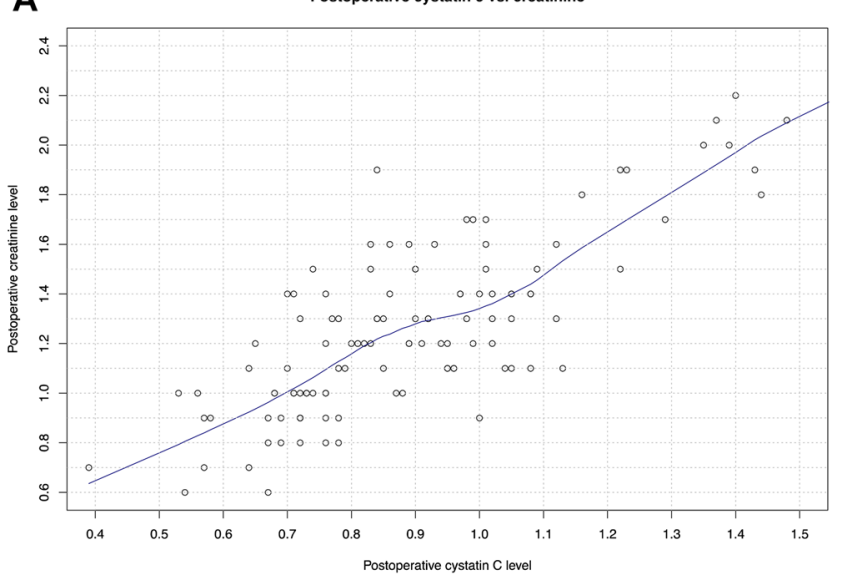

B

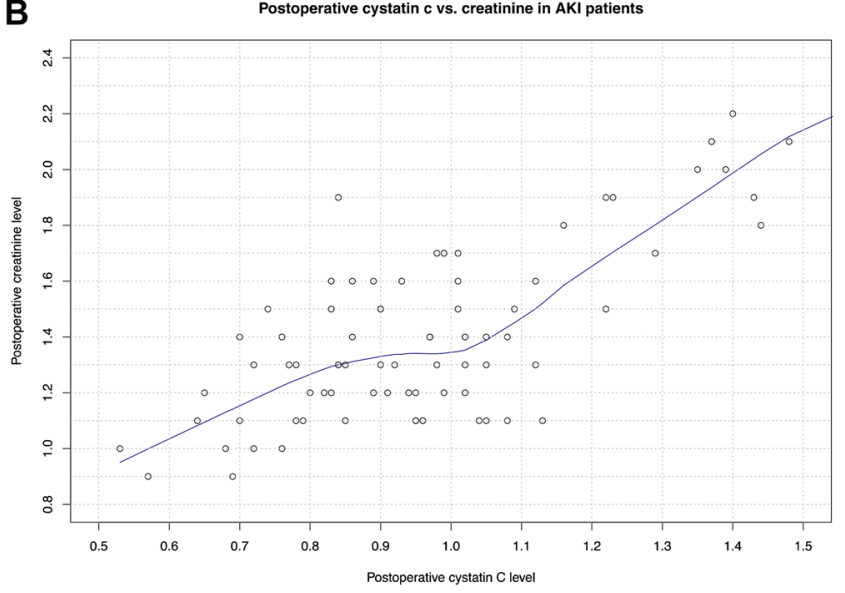

Fig. 1 Loess plots depicting the relationship between postoperative cystatin c level and postoperative creatinine level in A all examined patients and in $\mathbf{B}$ patients with acute kidney injury (AKI) after kidney surgery for renal cell carcinoma 
A

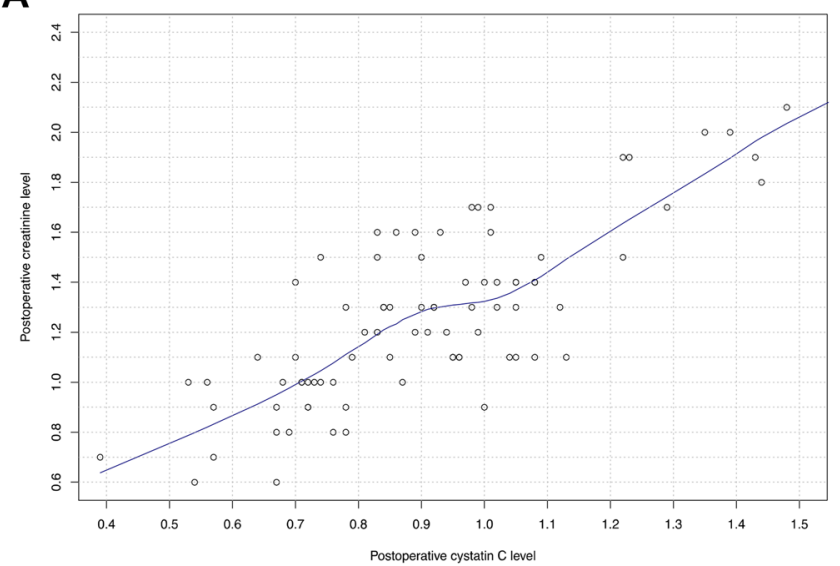

C.

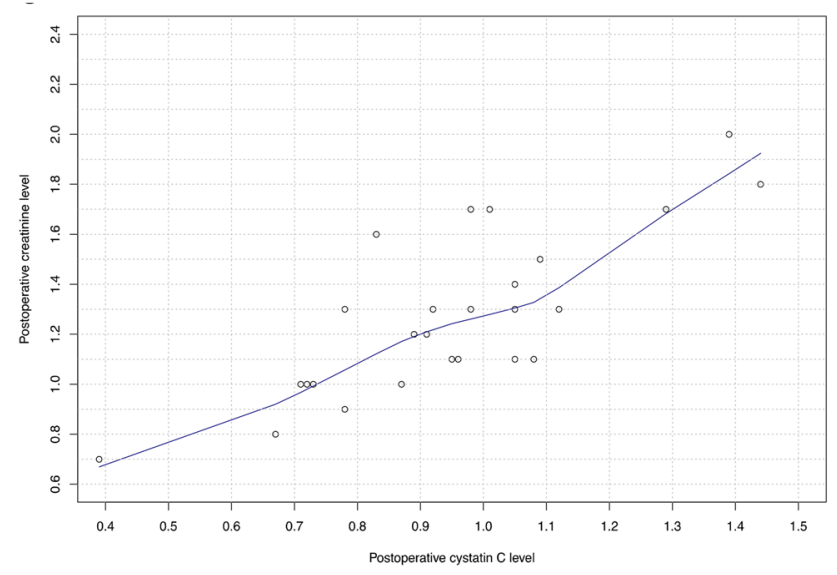

Fig. 2 Loess plots depicting the relationship between postoperative cystatin c level and postoperative creatinine level in $\mathbf{A}$ patients aged $\geq 50$ years in $\mathbf{B}$ patients aged $\geq 60$ years $\mathbf{C}$ patients

in previous studies [28]. Here especially patients with higher age and more comorbidities underwent more frequently RN. In consequence, due to preoperative comorbidity profile and non-nephron sparing $\mathrm{RN}$, these patients were at highest risk for postoperative elevated CysC levels, despite the fact that AKI rates between both groups did not differ. Taken together, further efforts should be made to provide nephronsparing surgery to all patients, whenever feasible, to avoid postoperative kidney function impairment.

However, it is also particularly important that approximately $30 \%$ of all patients with elevated postoperative CysC were not classified as AKI, according to traditional criteria [29]. Therefore, clinicians should be aware of patients with risk profile for kidney function impairment, which may be underestimated by usual creatinine-based AKI definitions, when cystatin $\mathrm{C}$ tests in clinical practice are not routinely performed. These risk factors may be mainly the surgical approach, diabetes and age, as also already investigated in previous publications $[11,30]$.
B

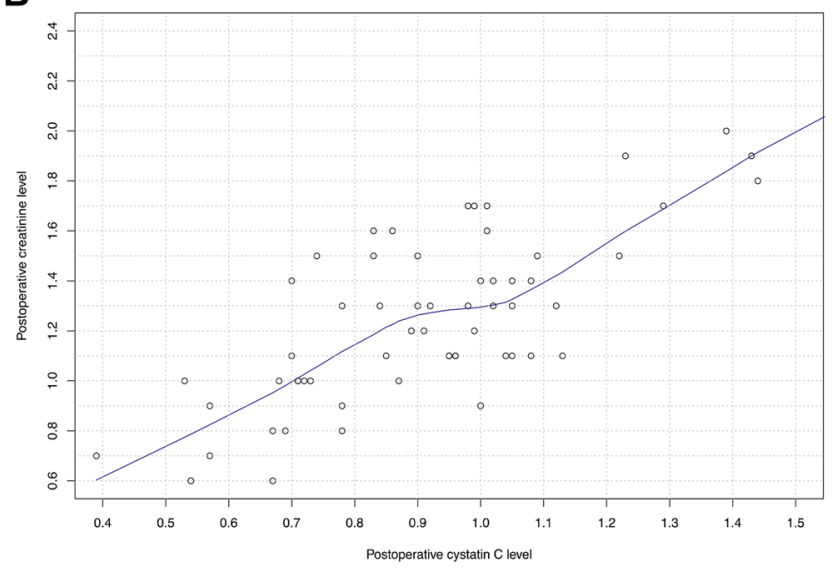

D

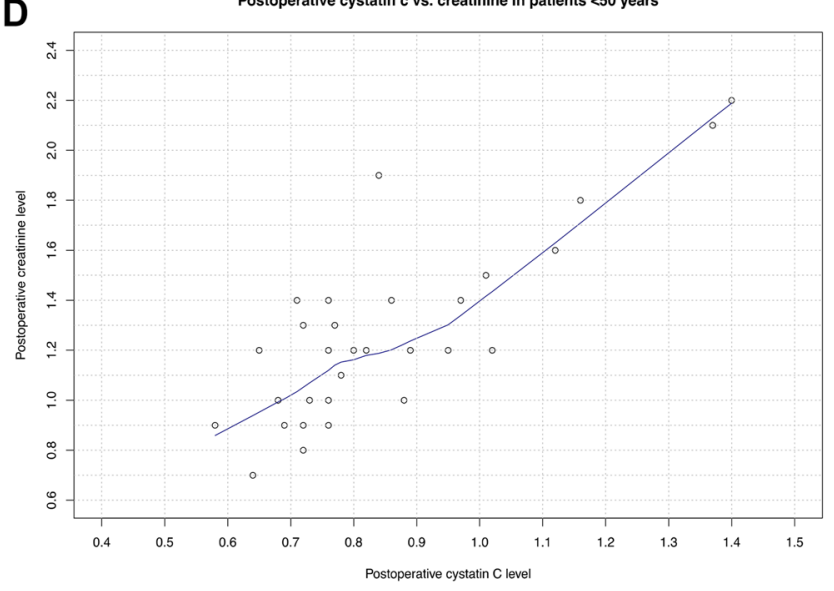

aged $\geq 70$ years and $\mathbf{D}$ patients aged $<50$ years after kidney surgery for renal cell carcinoma

Second, we also made important observation regarding cystatin $\mathrm{C}$ as a predictor for kidney function impairment at follow-up. Specifically, we observed in multivariable logistic regression models that preoperative cystatin $\mathrm{C}$ was an independent predictor of kidney function impairment in follow-up. Conversely, postoperative cystatin $\mathrm{C}$ level was not found to be such a predictor after adjusting for the above-mentioned risk factors of age, surgical approach and diabetes among others. Consequently, it is possible that a postoperative increase in the $\mathrm{CysC}$ level (measured on the first postoperative day) only reflects a physiological reaction on the performed surgery and is measured too early to predict valid long-term kidney function estimates. Conversely, the preoperative CysC level may better reflect the cumulative overall lifestyle and comorbidity-related kidney function and its potential to be of high risk for post-surgical impairment. These assumptions are also emphasized by the observations by Alesawi et al., where 
already five minutes after unclamping the kidney vessels an increase of the CysC level was observed [16].

Moreover, our observations were further validated in linear regression models, where an increase of the preoperative CysC blood level of $0.1 \mathrm{mg} / \mathrm{l}$ was independently associated with an eGFR reduction of $-5.8 \mathrm{ml} / \mathrm{min} / 1.73 \mathrm{~m}^{2}$ in the follow-up. To the best of our knowledge, we are the first to observe this important relationship of $\mathrm{Cys} C$ in a surgically treated cohort of RCC patients. In consequence, our data cannot be directly compared to previous studies. However, in a previous study investigating the effect of $\mathrm{CysC}$ in a donor nephrectomy cohort for living-donor kidney transplantation, similar observations have been also reported. Here, cystatin $\mathrm{C}$ concentration was also independently associated with the occurrence of CKD in follow-up [31]. Nonetheless, important differences exist between donor nephrectomy and RCC nephrectomy patients regarding baseline characteristics, such as age at surgery (44 vs. 60 years) or comorbidity profiles (for example diabetes proportions ( 0.7 vs. $13.3 \%$ ). In consequence, our findings provide an important and robust contribution for a specific RCC cohort regarding CysC as a predictor for kidney function impairment. Therefore, preoperative CysC levels can be used to estimate the extent of the kidney impairment after RCC surgery. The occurrence of CKD, as well as AKI is frequent in the cohort of patients undergoing RCC surgery. In consequence, a nephrology referral should be considered to address the increased risk for cardiovascular mortality, CKD progression and CKDrelated comorbidities in these patients, and especially in those with elevated preoperative levels of CysC.

Third, we also made important observation regarding postoperative CysC level as a marker for kidney function impairment. Specifically, we observed that regardless of rising postoperative $\mathrm{CysC}$ level in the range of approximately $0.9-1.0 \mathrm{mg} / \mathrm{l}$, the postoperative creatinine level remained at a plateau of $1.3 \mathrm{mg} / \mathrm{dl}$. However, for postoperative CysC below $0.9 \mathrm{mg} / \mathrm{l}$ and above $1.0 \mathrm{mg} / \mathrm{l}$ a linear correlation between postoperative cystatin $\mathrm{C}$ and creatinine was observed. The same observations were further made in subgroup analyses of AKI patients and different age groups. These observations are particularly noteworthy, since in a postoperative setting kidney function impairment might not be detected in the range around $1.3 \mathrm{mg} / \mathrm{dl}$ creatinine value. In consequence, $\mathrm{Cys} C \mathrm{C}$ might be a better marker for postoperative kidney function measurement. Moreover, a previous study by Roberts et al. showed that kidney function may be overestimated in older patients, when creatinine-based estimates are used [19]. However, in the current study, our observations suggest that $\mathrm{Cys} C$ results in the same outcomes in elderly patients as in younger patients.

Our study has several limitations and needs to be interpreted in its retrospective, single-institution design. Some of our observations and findings may be limited by sample size, especially in subgroup analyses addressing elderly patients. Moreover, we relied on the MDRD formula for eGFR estimates, which may underestimate its values, relative to other formulas. Also, patients' medication may have impacted eGFR estimates. Finally, only approximately the half of all the surgical treated patients of the current study participated in the follow-up, which may bias follow-up results and predictions. Follow-up was not obtained at standardized time points after RCC surgery. In consequence, all of the above findings need to be ideally further validated in RCC cohorts with bigger sample sizes.

Taken together, our results suggest that baseline patient characteristics such as age, as well as the comorbidity profile (especially diabetes) and the surgical approach identify patients with high risk of postoperative elevated CysC level and consecutive renal function impairment. Moreover, elevated CysC detected approximately $30 \%$ of patients with reduced kidney function, which may not have been identified through traditional creatinine-based AKI definitions. Second, we also observed that the preoperative $\mathrm{CysC}$ level was a predictor for long-term kidney function impairment and CKD prediction, while postoperative $\mathrm{CysC}$ level was not. However, the postoperative CysC level seems to be more sufficient to uncover early postoperative kidney function impairment than creatine values, especially in a creatinine range around $1.3 \mathrm{mg} / \mathrm{dl}$.

\section{Acknowledgements None.}

Author's contributions WM: manuscript writing-original draft preparation, protocol/project development, data analysis. HY: protocol/project development, data analysis. UA: manuscript writing/editing. WC: data collection or management. WM: data collection or management. BA: supervision, writing — writing/editing. FM: supervision, writingwriting/editing. CFKH: supervision, writing-writing/editing. MCP: manuscript writing/editing. LM: data analysis, manuscript writingoriginal draft preparation, supervison.

Funding Open Access funding enabled and organized by Projekt DEAL.

Data availability All datasets generated for this study are included in the manuscript.

Code availability On request used software R statistics (version 3.6.1).

\section{Declarations}

Conflict of interest The authors declare that they have no conflict of interest.

Ethical approval The current study was performed in accordance with the Declaration of Helsinki and approved by the local ethic committee of the University Hamburg-Eppendorf (number PV4219).

Consent to participate Not applicable. 
Consent for publication Not applicable.

Open Access This article is licensed under a Creative Commons Attribution 4.0 International License, which permits use, sharing, adaptation, distribution and reproduction in any medium or format, as long as you give appropriate credit to the original author(s) and the source, provide a link to the Creative Commons licence, and indicate if changes were made. The images or other third party material in this article are included in the article's Creative Commons licence, unless indicated otherwise in a credit line to the material. If material is not included in the article's Creative Commons licence and your intended use is not permitted by statutory regulation or exceeds the permitted use, you will need to obtain permission directly from the copyright holder. To view a copy of this licence, visit http://creativecommons.org/licenses/by/4.0/.

\section{References}

1. Van Poppel H, Becker F, Cadeddu JA et al (2011) Treatment of localised renal cell carcinoma. Eur Urol 60(4):662-672. https://doi. org/10.1016/j.eururo.2011.06.040

2. Nocera L, Collà Ruvolo C, Stolzenbach LF et al (2021) Tumor stage and substage predict cancer-specific mortality after nephrectomy for nonmetastatic renal cancer: histological subtype-specific validation. Eur Urol Focus. https://doi.org/10.1016/j.euf.2021.02.009

3. Würnschimmel C, Ruvolo CC, Nocera L et al (2021) Race/ethnicity determines life expectancy in surgically treated T1aNOM0 renal cell carcinoma patients. Eur Urol Focus. https://doi.org/10.1016/j.euf. 2021.02.004

4. Huang WC, Levey AS, Serio AM et al (2006) Chronic kidney disease after nephrectomy in patients with renal cortical tumours: a retrospective cohort study. Lancet Oncol 7(9):735-740. https://doi. org/10.1016/S1470-2045(06)70803-8

5. Thompson RH, Lane BR, Lohse CM et al (2012) Renal function after partial nephrectomy: effect of warm ischemia relative to quantity and quality of preserved kidney. Urology 79(2):356-360. https:// doi.org/10.1016/j.urology.2011.10.031

6. Capitanio U, Larcher A, Cianflone F et al (2020) Hypertension and cardiovascular morbidity following surgery for kidney cancer. Eur Urol Oncol 3(2):209-215. https://doi.org/10.1016/j.euo.2019.02.006

7. Manjunath G, Tighiouart H, Ibrahim H et al (2003) Level of kidney function as a risk factor for atherosclerotic cardiovascular outcomes in the community. J Am Coll Cardiol 41(1):47-55. https://doi.org/ 10.1016/s0735-1097(02)02663-3

8. Ljungberg B, Albiges L, Bensalah K et al. EAU Guidelines on Renal Cell Carcinoma (2020) EAU Guidelines Office, Arnhem, The Netherlands. http://uroweb.org/guidelines/compilations-of-all-guidelines/

9. Barlow LJ, Korets R, Laudano M, Benson M, McKiernan J (2010) Predicting renal functional outcomes after surgery for renal cortical tumours: a multifactorial analysis. BJU Int 106(4):489-492. https:// doi.org/10.1111/j.1464-410X.2009.09147.X

10. Go AS, Chertow GM, Fan D, McCulloch CE, Hsu C (2004) Chronic kidney disease and the risks of death, cardiovascular events, and hospitalization. N Engl J Med 351(13):1296-1305. https://doi.org/ 10.1056/NEJMoa041031

11. Satasivam P, Reeves F, Rao K et al (2015) Patients with medical risk factors for chronic kidney disease are at increased risk of renal impairment despite the use of nephron-sparing surgery. BJU Int 116(4):590-595. https://doi.org/10.1111/bju.13075

12. Schmid M, Abd-El-Barr AER, Gandaglia G et al (2014) Predictors of 30-day acute kidney injury following radical and partial nephrectomy for renal cell carcinoma. Urol Oncol 32(8):1259-1266. https:// doi.org/10.1016/j.urolonc.2014.05.002

13. Gourishankar S, Courtney M, Jhangri GS, Cembrowski G, Pannu N (2008) Serum cystatin C performs similarly to traditional markers of kidney function in the evaluation of donor kidney function prior to and following unilateral nephrectomy. Nephrol Dial Transplant Off Publ Eur Dial Transpl Assoc 23(9):3004-3009. https://doi.org/ 10.1093/ndt/gfn114

14. Herget-Rosenthal S, Pietruck F, Volbracht L, Philipp T, Kribben A (2005) Serum cystatin C - a superior marker of rapidly reduced glomerular filtration after uninephrectomy in kidney donors compared to creatinine. Clin Nephrol 64(1):41-46. https://doi.org/10. 5414/cnp64041

15. Shlipak MG, Matsushita K, Ärnlöv J et al (2013) Cystatin C versus creatinine in determining risk based on kidney function. $\mathrm{N}$ Engl $\mathrm{J}$ Med 369(10):932-943. https://doi.org/10.1056/NEJMoa1214234

16. Alesawi A, Nadeau G, Bergeron A, Dujardin T, Lacombe L, Caumartin Y (2014) Cystatin C for early detection of acute kidney injury after laparoscopic partial nephrectomy. Urol Ann 6(4):298-304. https://doi.org/10.4103/0974-7796.140988

17. Yong Z, Pei X, Zhu B, Yuan H, Zhao W (2017) Predictive value of serum cystatin $\mathrm{C}$ for acute kidney injury in adults: a meta-analysis of prospective cohort trials. Sci Rep 7:41012. https://doi.org/10.1038/ srep41012

18. Rothenbacher D, Rehm M, Iacoviello L et al (2020) Contribution of cystatin C- and creatinine-based definitions of chronic kidney disease to cardiovascular risk assessment in 20 population-based and 3 disease cohorts: the BiomarCaRE project. BMC Med 18(1):300. https://doi.org/10.1186/s12916-020-01776-7

19. Roberts GW, Ibsen PM, Schiøler CT (2009) Modified diet in renal disease method overestimates renal function in selected elderly patients. Age Ageing 38(6):698-703. https://doi.org/10.1093/ageing/afp168

20. Hojs R, Bevc S, Ekart R, Gorenjak M, Puklavec L (2006) Serum cystatin $\mathrm{C}$ as an endogenous marker of renal function in patients with mild to moderate impairment of kidney function. Nephrol Dial Transplant Off Publ Eur Dial Transpl Assoc 21(7):1855-1862. https://doi.org/10.1093/ndt/gfl073

21. Villa P, Jiménez M, Soriano M-C, Manzanares J, Casasnovas P (2005) Serum cystatin C concentration as a marker of acute renal dysfunction in critically ill patients. Crit Care Lond Engl 9(2):R139143. https://doi.org/10.1186/cc3044

22. Levey ASGT, Kusek JW, Beck GL, MDRD Study Group (2000) A simplified equation to predict glomerular filtration rate from serum creatinine abstract. J Am Soc Nephrol 11:155A

23. Levey AS, Bosch JP, Lewis JB, Greene T, Rogers N, Roth D (1999) A more accurate method to estimate glomerular filtration rate from serum creatinine: a new prediction equation. Modification of Diet in Renal Disease Study Group. Ann Intern Med 130(6):461-470. https://doi.org/10.7326/0003-4819-130-6-199903160-00002

24. Reference Keys. Kidney Int Suppl. 2012;2(1): 4. https://doi.org/10. 1038/kisup.2012.4

25. Levey AS, Eckardt K-U, Dorman NM et al (2020) Nomenclature for kidney function and disease: report of a kidney disease: improving Global Outcomes (KDIGO) Consensus Conference. Kidney Int 97(6):1117-1129. https://doi.org/10.1016/j.kint.2020.02.010

26. RCT (2017) R: a language and environment for statistical computing. https://www.r-project.org2017.

27. Thomas AA, Demirjian S, Lane BR et al (2011) Acute kidney injury: novel biomarkers and potential utility for patient care in urology. Urology 77(1):5-11. https://doi.org/10.1016/j.urology.2010.05.004

28. von Klot C, Herrmann TR, Wegener G et al (2013) Age distribution for partial and radical nephrectomy: whose nephrons are being spared? Adv Ther 30(10):924-932. https://doi.org/10.1007/ s12325-013-0061-0

29. Makris K, Spanou L (2016) Acute kidney injury: definition, pathophysiology and clinical phenotypes. Clin Biochem Rev 37(2):85-98

30. Cho A, Lee JE, Kwon G-Y et al (2011) Post-operative acute kidney injury in patients with renal cell carcinoma is a potent risk factor for 
new-onset chronic kidney disease after radical nephrectomy. Nephrol Dial Transplant Off Publ Eur Dial Transpl Assoc 26(11):3496-3501. https://doi.org/10.1093/ndt/gfr094

31. Bang J-Y, Kim S-O, Kim S-G, Song J-G, Hwang GS (2017) Cystatin-C is associated with partial recovery of kidney function and progression to chronic kidney disease in living kidney donors: observational study. Medicine (Baltimore) 96(5):e6037. https://doi. org/10.1097/MD.0000000000006037

Publisher's Note Springer Nature remains neutral with regard to jurisdictional claims in published maps and institutional affiliations. 